\title{
Evolution of Validated Biomarkers and Intraoperative Parameters in the Development of Postoperative ARDS
}

\author{
Hemang Yadav MBBS, Adam Bartley MSc, Sheila Keating PhD, Laurie A Meade RN, \\ Philip J Norris MD, Rickey E Carter PhD, Ognjen Gajic MD, and Daryl J Kor MD
}

\begin{abstract}
BACKGROUND: Patients who develop ARDS from medical or traumatic causes typically present after the inciting event has already occurred. Postoperative ARDS is unique in that the inciting insult potentially responsible for ARDS is known ahead of time, which provides an opportunity to study the early pathophysiology of ARDS. The objective of this study was to better understand the early pathophysiology of postoperative ARDS through a temporal analysis of key biomarkers of interest. METHODS: We performed a case-control study of adults undergoing elective thoracic, aortic vascular, or cardiac surgery, which placed them at increased risk of developing postoperative ARDS. Biomarkers were measured at baseline, $2 \mathrm{~h}$, and $6 \mathrm{~h}$ after the key intraoperative event believed to be responsible for ARDS. RESULTS: Of the 467 subjects enrolled, 26 developed ARDS and were matched to non-ARDS controls 1:2 based on age, sex, surgical procedure, and surgical lung injury prediction score. Patients with ARDS were more likely to have lower preoperative albumin $(P=.029)$, longer surgery $(P=.007)$, larger amounts of intraoperative fluid $(P=.036)$, and higher intraoperative peak inspiratory pressures $(P=.006)$. Baseline plasminogen activator inhibitor-1 levels were higher in the ARDS group $(P=.03)$. Changes in postoperative biomarker levels from baseline were greater in the ARDS group for interleukin-8 (baseline to $6 \mathrm{~h}, P=.02$ ) and surfactant protein-D (baseline to $2 \mathrm{~h}, P=.009$ ). CONCLUSIONS: Our study supported the hypothesis that dysregulated coagulation, inflammation, and epithelial injury are pathophysiologic features of early postoperative ARDS. Interleukin-8, plasminogen activator-1, and surfactant protein-D may help predict development of postoperative ARDS. Key words: ARDS; postoperative complications; respiratory failure; prevention; biomarker. [Respir Care 2018;63(11):1331-1340. (C) 2018 Daedalus Enterprises]
\end{abstract}

\section{Introduction}

ARDS is a potentially devastating cause of postoperative respiratory failure. ${ }^{1}$ With advances in organ support

\footnotetext{
Drs Yadav and Gajic are affiliated with Division of Pulmonary and Critical Care Medicine, Mayo Clinic, Rochester, Minnesota. Mr Bartley and Dr Carter are affiliated with Department of Health Sciences Research, Mayo Clinic, Rochester, Minnesota. Drs Keating and Norris are affiliated with Blood Systems Research Institute, San Francisco, California. Drs Keating and Norris are affiliated with University of California, San Francisco, California. Ms Meade and Dr Kor are affiliated with Department of Anesthesiology and Perioperative Medicine, Mayo Clinic, Rochester, Minnesota.
}

Supplementary material related to this paper is available at http:// www.rcjournal.com.

The authors have disclosed no conflicts of interest. and improved treatment of underlying conditions, ARDSassociated mortality has decreased, from nearly $100 \%$ to $<40 \%$, over the past 20 years. $^{2}$ However, the mortality and impact of postsurgical ARDS on patient-centered

Funding was provided by National Center for Advancing Translational
Sciences grant UL1 TR000135, National Heart, Lung, and Blood Insti-
tute grant K23 HL112855, the Mayo Clinic Critical Care Research Subtute grant $\mathrm{K} 23$
committee.

Preliminary data from this study were presented at the annual meeting of the American Thoracic Society, May 16-21, 2014, San Diego, California.

Correspondence: Hemang Yadav MBBS, Department of Pulmonary and Critical Care Medicine, Mayo Clinic, 200 1st Street SW, Rochester, MN 55905. E-mail: yadav.hemang@mayo.edu.

DOI: $10.4187 /$ respcare. 06103 
outcomes remain substantial. ${ }^{3}$ With the exception of preventing further iatrogenic lung injury through lung-protective mechanical ventilation ${ }^{4,5}$ and conservative fluid management, ${ }^{6}$ no effective ARDS therapeutic strategies presently exist. A selection of previous trials (Yadav et $\mathrm{al}^{7}$ ), that evaluated treatments that target the pathophysiologic pathways that underlie ARDS failed to improve

See the Related Editorial on Page 1455

patient outcomes despite compelling preclinical data for their efficacy. The negative trials were hypothesized to be a consequence of attempted intervention too far along the ARDS disease course, after development of the full-blown clinical syndrome. Consequently, given the absence of effective treatment options, prevention of ARDS has become a key strategic priority. Two critical barriers to progress in ARDS prevention include an incomplete understanding of ARDS mechanisms and an inability to reliably identify patients at high risk in a time-efficient manner. ${ }^{7}$

Previous studies identified plasma biologic markers that represented the varied pathophysiologic processes believed to be involved in ARDS. These include interleukin (IL) $6,{ }^{8-14} \mathrm{IL}-8,{ }^{8-13,15,16}$ the soluble receptor for advanced glycation end products (sRAGE), ${ }^{11,14,17-19}$ angiopoietin2,11,20-22 von Willebrand factor, ${ }^{8,11,23-25}$ intercellular adhesion molecule-1, $, 111,15,26,27$ surfactant protein-D, $8,11,28$ and plasminogen activator inhibitor-1 (PAI-1). ${ }^{8,11,15,29,30}$ Importantly, all of these previous studies only enrolled subjects with established ARDS, often days after the clinical insult responsible for the development of ARDS. Characterizations of the change in biomarkers levels from a premorbid healthy state to early ARDS are lacking. Postoperative ARDS is unique in that the clinical insult potentially responsible for ARDS can be predicted ahead of time, which allows for this novel analysis. Moreover, previous studies indicate that the primary pathophysiologic pathways that lead to ARDS may depend on the clinical circumstances. ${ }^{31}$ Limited data exist regarding changes in biomarkers in patients with postsurgical ARDS

Our objective in this study was 2-fold. First, we aimed to better understand the pathogenesis of postoperative ARDS through an analysis of the temporal profile of 8 biomarkers that represent the key pathophysiologic processes implicated in ARDS development (inflammation, endothelial and epithelial injury, and dysregulated coagulation). Second, we aimed to demonstrate that biomarkers are elevated within hours of the clinical insult responsible for ARDS, well before the development of the full-blown clinical syndrome. This study would form the foundation of future studies that integrate any candidate biomarkers

\section{QUICK LOOK}

\section{Current knowledge}

Limited data exist regarding the pathophysiologic changes that occur very early in the development of ARDS. Postoperative ARDS is unique in that the inciting event is known ahead of time, which provides an opportunity to study the early pathophysiology of ARDS.

\section{What this paper contributes to our knowledge}

Patients who developed ARDS had higher interleukin-8, plasminogen-activator-1, and surfactant protein-D as well as elevated intraoperative peak inspiratory pressures. Both the biomarker and clinical findings were evident within hours, well before the development of the full ARDS clinical syndrome.

identified with clinical prediction models with a view to improved ARDS risk prediction. ${ }^{22}$

\section{Methods}

This was a prospective observational single-center case-control study of subjects undergoing thoracic, aortic vascular, or cardiac surgery between January 2010 and July 2014, which placed them at high risk of developing postoperative ARDS. Mayo Clinic Institutional Review Board approved this study (IRB 11-004138), and written informed consent was obtained from all study participants.

\section{Study Population}

The study population consisted of consecutive, consenting adults (ages $\geq 18 \mathrm{y}$ ) who were undergoing elective cardiac, aortic vascular, or thoracic (lung resection or esophageal) surgery with an estimated risk of postoperative ARDS of $>10 \%$ (surgical lung injury prediction score of $\geq 27$ ) (see the supplementary materials at http://www. rcjournal.com). ${ }^{1}$ Patients were excluded if they had emergency surgery, preexisting bilateral pulmonary infiltrates, recent high-risk surgery, or were receiving mechanical ventilation within $30 \mathrm{~d}$ of surgery.

\section{Primary Outcome: Development of ARDS}

The outcome of interest is postoperative ARDS. Postoperative ARDS was determined by using the 2012 Berlin definition for ARDS. ${ }^{32}$ ARDS ascertainment proceeded in 3 steps. All the patients were initially screened by a member of the study team (Laurie Meade), who calculated the 
$\mathrm{P}_{\mathrm{aO}} / \mathrm{F}_{\mathrm{IO}_{2}}$ and reviewed the chest radiographs of the study subjects. Subjects with a $\mathrm{P}_{\mathrm{aO}} / \mathrm{F}_{\mathrm{IO}_{2}}$ value of $\leq 300$ and a chest radiograph with any findings suggestive of bilateral infiltrates, edema, or congestion were considered screenpositive cases. Two experts (HY, DJK) with substantial experience in ARDS adjudication then reviewed these screen-positive cases. The inter-observer $\kappa$ for ARDS diagnosis was 0.62 (95\% CI 0.48-0.77). Prevalence-adjusted bias-adjusted $\kappa$ was $0.81 .{ }^{33}$ Disagreements were resolved by a third consulting expert (OG).

\section{Predictor Variables}

The primary predictor variables were plasma levels of IL-6, IL-8, surfactant protein-D, von Willebrand factor, angiopoietin-2, intercellular adhesion molecule-1, PAI-1, and sRAGE. These were quantitatively analyzed in plasma samples collected at 3 distinct time points. The first sample was obtained after the induction of anesthesia (baseline level). The timing of the second sample varied, depending on the surgical procedure. For patients undergoing cardiac surgery, the second sample was obtained $2 \mathrm{~h}$ after separation from the cardiopulmonary bypass. For subjects undergoing aortic vascular surgery, the second sample was obtained $2 \mathrm{~h}$ after aortic cross clamp removal. For subjects undergoing thoracic (non-cardiac) surgery, the second sample was obtained $2 \mathrm{~h}$ after return to 2-lung ventilation. The second sample acquisition time was timed to immediately follow the major intraoperative insult believed associated with development of lung injury. The third sample was collected at $4 \mathrm{~h}$ after the acquisition of the second sample (ie, $6 \mathrm{~h}$ after the intraoperative insult believed to be responsible for ARDS). Further details about blood sample handling and analysis as well as clinical data extraction and handling are outlined in the appendix (see the supplementary materials at http://www.rcjournal.com).

\section{Statistical Analysis}

Sample size calculations assumed an ARDS incidence of $10 \%$, based on a surgical lung injury prediction score of $\geq 27 .{ }^{1}$ By using 2 controls for each case, we estimated an $80 \%$ power to detect an effect size of $0.49(\alpha=0.05$, 2 -sided). More specifically, this represented a 0.49 SD separation in mean values in the participants who developed ARDS versus those who did not develop ARDS. The subjects with ARDS were matched to non-ARDS controls on the surgical lung injury prediction score, age, sex, and type of surgical procedure. Categorical variables were summarized as frequency (\%) and were compared by using the chi-square test or the Fisher exact test, as appropriate. Continuous variables were expressed as mean $\pm \mathrm{SD}$ or median with interquartile range (IQR), as appropriate. Continuous variables were compared by using $t$ tests for data that were normally distributed and by using a Wilcoxon analysis for all other data. Conditional logistic regression models were fit for each biomarker in univariate analyses at 3 time points as well as the change from baseline to $2 \mathrm{~h}$ and baseline to $6 \mathrm{~h}$. Statistical analysis was performed by using SPSS Version 22 (IBM, Armonk, New York). All $P$ values reported were 2-sided and were not adjusted for multiple comparisons.

\section{Results}

A total of 467 subjects were enrolled in the study (Fig. 1). Twenty-six subjects developed ARDS (5.6\%), matched 1:2 to 51 controls on age, sex, surgical procedure, and surgical lung injury prediction score. One case was matched 1:1 because there were insufficient control subjects with a matching surgery (pericardiectomy). The median time to ARDS development was $43.9 \mathrm{~h}$ (19.1-78.3 h).

\section{Preoperative and Perioperative Clinical Variables}

Baseline subject characteristics are outlined in Table 1. Preoperative characteristics of the 26 subjects with ARDS and 51 non-ARDS matched controls are outlined in Table 2. Intraoperative characteristics are outlined in Table 3. Notably, the ARDS cohort had higher fluid administration $(11,475 \pm 6,267 \mathrm{~mL}$ vs $8,477 \pm 4,430 \mathrm{~mL}, P=.036)$ and higher peak inspiratory pressures $\left(22.7 \pm 6.5 \mathrm{~cm} \mathrm{H}_{2} \mathrm{O}\right.$ vs $\left.18.8 \pm 4.9 \mathrm{~cm} \mathrm{H}_{2} \mathrm{O}, P=.006\right)$. There was a trend to more intraoperative transfusions in the ARDS cohort $(2,374 \pm 3,129 \mathrm{~mL}$ vs $1,378 \pm 1,894 \mathrm{~mL}, P=.09)$. There were no differences in the frequency and duration of intraoperative events thought to be related to the development of postoperative ARDS (one-lung ventilation, aortic cross clamping, cardiopulmonary bypass).

\section{Outcomes}

Outcomes of the ARDS and non-ARDS cohorts are outlined in Table 4. Admission severity of illness as assessed by using APACHE (Acute Physiology and Chronic Health Evaluation) III and the Sequential Organ Failure Assessment scoring system was not different between the groups. In those with ARDS, the severity was mild in 7 (26.9\%), moderate in $5(19.2 \%)$, and severe in $14(53.8 \%)$. Those with ARDS had longer ICU (3.5 d [IQR 1.1-5.9 d] vs $1.1 \mathrm{~d}$ [IQR $0.9-2.9 \mathrm{~d}$ ], $P=.036$ ) and hospital lengths of stay (14.8 d [IQR 10.3-19.3 d] vs 7.3 d [IQR 5.4-9.8 d], $P<.001)$, and fewer ventilator-free days $(P<.001)$. Those subjects who developed ARDS had higher mortality (mortality at $28 \mathrm{~d}: 11.5 \%$ vs $0 \%, P=.034$; and mortality in the hospital: $15.4 \%$ vs $0 \%, P=.006$ ). 


\section{BIOMARKERS IN POSTOPERATIVE ARDS}

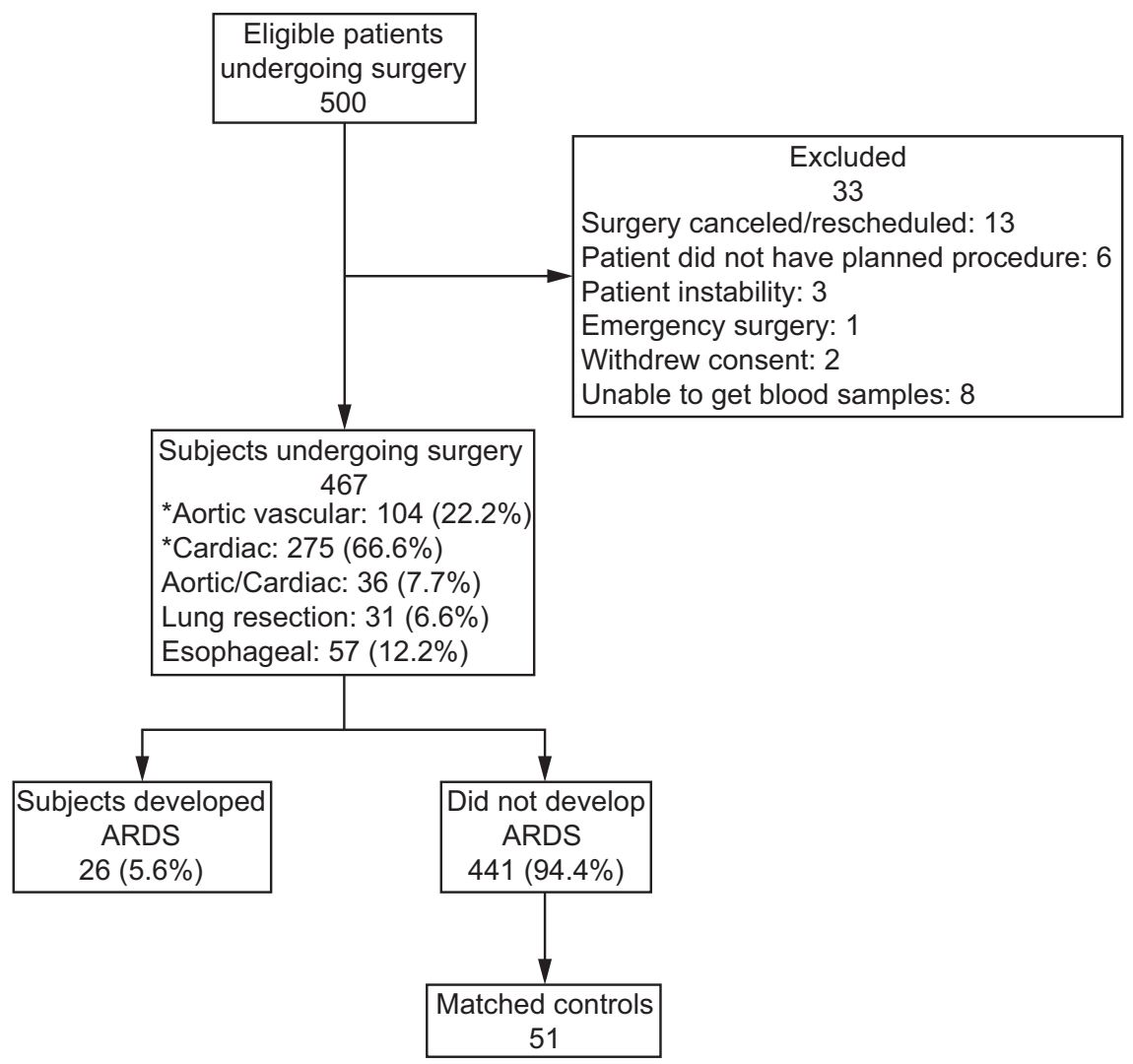

Fig. 1. Study flow chart. Patient instability reflects planned elective surgeries that were expedited as emergency surgeries due to patient need. Controls were matched 1:2 for age, the surgical lung injury prediction (SLIP) score, sex, and surgical procedure. * Thirty-six subjects had combined procedures and were counted in each category.

Table 1. Baseline Characteristics and Surgery Descriptions of Enrolled Subjects

\begin{tabular}{|c|c|c|c|c|c|}
\hline \multirow[b]{2}{*}{ Variable } & \multirow[b]{2}{*}{$\operatorname{ARDS}(n=26)$} & \multicolumn{4}{|c|}{ No ARDS } \\
\hline & & $\begin{array}{c}\text { All Non-ARDS } \\
\text { Subjects }(n=441)\end{array}$ & $P$ & $\begin{array}{c}\text { Matched } \\
\text { Controls }(n=51)\end{array}$ & $P$ \\
\hline Male, $n(\%)$ & $20(76.9)$ & $323(73.2)$ & .67 & $37(72.5)$ & .68 \\
\hline Age, mean $\pm \mathrm{SD}, \mathrm{y}$ & $63.3 \pm 13.8$ & $65.4 \pm 11.7$ & .47 & $62.5 \pm 13.4$ & .81 \\
\hline Surgical lung injury prediction score, mean \pm SD & $37.6 \pm 8.2$ & $35 \pm 5.7$ & .11 & $36.9 \pm 6.5$ & .72 \\
\hline Type of surgery, $n(\%)$ & & & .007 & & $>.99$ \\
\hline Aortic vascular only & $11(42.3)$ & $57(12.9)$ & & $22(43.1)$ & \\
\hline Coronary artery bypass grafting only & $4(15.4)$ & $102(23.1)$ & & $8(15.7)$ & \\
\hline Valve only & $1(3.8)$ & $104(23.6)$ & & $2(3.9)$ & \\
\hline Coronary artery bypass grafting and valve & $1(3.8)$ & $58(13.2)$ & & $2(3.9)$ & \\
\hline Coronary artery bypass grafting and aortic vascular & $0(0)$ & $7(1.6)$ & & $0(0)$ & \\
\hline Valve and aortic vascular & $0(0)$ & $20(4.5)$ & & $0(0)$ & \\
\hline Coronary artery bypass grafting, aortic vascular and valve & $1(3.8)$ & $8(1.8)$ & & $2(3.9)$ & \\
\hline Pericardiectomy & $2(7.7)$ & $3(0.7)$ & & $3(5.9)$ & \\
\hline Esophageal & $5(19.2)$ & $52(11.8)$ & & $10(19.6)$ & \\
\hline Lobectomy & $1(3.8)$ & $19(4.3)$ & & $2(3.9)$ & \\
\hline Pneumonectomy & $0(0)$ & $2(0.5)$ & & $0(0)$ & \\
\hline Wedge resection & $0(0)$ & $3(0.7)$ & & $0(0)$ & \\
\hline Mediastinoscopy & $0(0)$ & $3(0.7)$ & & $0(0)$ & \\
\hline
\end{tabular}


Table 2. Preoperative Characteristics of Subjects With ARDS and Non-ARDS Matched Controls

\begin{tabular}{|c|c|c|c|}
\hline Preoperative Variable & $\begin{array}{c}\text { ARDS } \\
(n=26)\end{array}$ & $\begin{array}{l}\text { Non-ARDS } \\
\text { Controls } \\
(n=51) \\
\end{array}$ & $P$ \\
\hline Surgery length, mean $\pm \mathrm{SD}$, min & $486 \pm 161$ & $375 \pm 171$ & .007 \\
\hline $\mathrm{BMI}$, mean $\pm \mathrm{SD}, \mathrm{kg} / \mathrm{m}^{2}$ & $30.4 \pm 8.2$ & $28.6 \pm 5.4$ & \\
\hline ASA, $n(\%)$ & & & .04 \\
\hline I & $0(0)$ & $0(0)$ & \\
\hline II & $1(3.8)$ & $6(11.8)$ & \\
\hline III & $25(96.2)$ & $38(74.5)$ & \\
\hline IV & $0(0)$ & $7(13.7)$ & \\
\hline \multicolumn{4}{|l|}{ Preoperative medications, $n(\%)$} \\
\hline Amiodarone & $1(3.8)$ & $2(3.9)$ & .99 \\
\hline Statin & $13(50)$ & $16(31.4)$ & .11 \\
\hline Systemic steroids & $3(11.5)$ & $2(3.9)$ & .21 \\
\hline Inhaled steroids & $10(38.5)$ & $9(17.6)$ & .05 \\
\hline Aspirin & $11(42.3)$ & $22(43.1)$ & .94 \\
\hline Immunosuppression & $3(11.5)$ & $2(3.9)$ & .21 \\
\hline Chemotherapy & $1(3.8)$ & $6(11.8)$ & .22 \\
\hline \multicolumn{4}{|l|}{ Preexisting medical conditions, $n(\%)$} \\
\hline Liver cirrhosis & $1(3.8)$ & $1(2)$ & .63 \\
\hline Diabetes mellitus & $7(26.9)$ & $9(17.6)$ & .35 \\
\hline COPD & $9(34.6)$ & $12(23.5)$ & .31 \\
\hline ILD & $0(0)$ & $0(0)$ & $>.99$ \\
\hline Gastroesophageal reflux disease & $7(26.9)$ & $16(31.4)$ & .69 \\
\hline ESRD & $0(0)$ & $0(0)$ & $>.99$ \\
\hline CKD & $4(15.4)$ & $11(21.6)$ & .51 \\
\hline Advanced cancer & $1(3.8)$ & $2(3.9)$ & .99 \\
\hline Heart failure & $5(19.2)$ & $9(17.6)$ & .87 \\
\hline Hematologic malignancy & $0(0)$ & $2(3.9)$ & .36 \\
\hline Tobacco dependence & $9(34.6)$ & $10(19.6)$ & .16 \\
\hline Alcohol dependence & $2(7.7)$ & $4(7.8)$ & .98 \\
\hline \multicolumn{4}{|l|}{ Preoperative laboratory indices } \\
\hline Hemoglobin, mean $\pm \mathrm{SD}, \mathrm{g} / \mathrm{dL}$ & $13.3 \pm 1.8$ & $12.7 \pm 1.9$ & .19 \\
\hline $\begin{array}{l}\text { White blood cell count, } \\
\text { mean } \pm \mathrm{SD}\end{array}$ & $7.2 \pm 2.2$ & $6.7 \pm 2.2$ & .37 \\
\hline Platelet count, mean $\pm \mathrm{SD}$ & $194 \pm 52$ & $224 \pm 100$ & .09 \\
\hline Creatinine, mean $\pm \mathrm{SD}, \mathrm{mg} / \mathrm{dL}$ & $1 \pm 0.3$ & $1.1 \pm 0.4$ & .78 \\
\hline Albumin, mean $\pm \mathrm{SD}, \mathrm{g} / \mathrm{L}$ & $3.5 \pm 0.5$ & $4.2 \pm 0.4$ & .03 \\
\hline Bicarbonate, mean $\pm \mathrm{SD}$ & $25.1 \pm 3$ & $26.6 \pm 3.2$ & .15 \\
\hline $\begin{array}{l}\text { BMI }=\text { body mass index } \\
\text { ASA }=\text { American Society of Anesthesiology } \\
\text { ILD }=\text { interstitial lung disease } \\
\text { ESRD = end-stage renal disease } \\
\text { CKD = chronic kidney disease }\end{array}$ & & & \\
\hline
\end{tabular}

\section{Biomarker Analyses}

Baseline levels of all the biomarkers were compared between ARDS and non-ARDS cohorts (Fig. 2, see the supplementary materials at http://www.rcjournal.com). PAI-1 was significantly higher at baseline in subjects with ARDS compared with the non-ARDS controls and was the only biomarker that differed significantly between the 2 groups at baseline of the 8 biomarkers tested $(21,055$ $\mathrm{pg} / \mathrm{mL}[13,991-25,696 \mathrm{pg} / \mathrm{mL}]$ vs $11,469 \mathrm{pg} / \mathrm{mL}[8,639-$ $17,036 \mathrm{pg} / \mathrm{mL}], P=.03)$.

Absolute biomarker levels were then compared between the ARDS and non-ARDS groups at $2 \mathrm{~h}$ and $6 \mathrm{~h}$ for the 8 biomarkers studied. IL-8 levels were significantly higher at the 2-h $(P=.048)$ and 6 -h $(P=.02)$ time points in subjects with ARDS compared with the non-ARDS controls. The sRAGE was significantly higher in the ARDS group at the 6-h time point $(P=.049)$ but not at the 2 -h time point $(P=.13)$. The PAI-1 levels were also significantly higher in the ARDS group at $6 \mathrm{~h}(P=.02)$ but not at $2 \mathrm{~h}(P=.058)$. Absolute biomarker levels did not differ at the 2-h and 6-h time points for the other biomarkers studied (IL-6, surfactant protein-D, angiopoietin-2, intercellular adhesion molecule-1, and von Willebrand factor).

Also, we compared the change in biomarker levels between baseline and $2 \mathrm{~h}$, and between baseline and $6 \mathrm{~h}$. The change in IL-8 was significantly greater in the ARDS group $\left(\Delta \mathrm{IL}-8_{0-6 \mathrm{~h}}: 56 \mathrm{pg} / \mathrm{mL}[10-279 \mathrm{pg} / \mathrm{mL}]\right.$ vs $17 \mathrm{pg} / \mathrm{mL}[9-32$ $\mathrm{pg} / \mathrm{mL}] P=.02$ ). There was a trend toward a higher $\Delta \mathrm{IL}-8_{0-2 \mathrm{~h}}$ in the ARDS group, but this did not reach statistical significance $(P=.052)$. There also were trends toward higher deltas for sRAGE $\left(\Delta \mathrm{sRAGE}_{0-6 \mathrm{~h}}: P=.063\right)$, and angiopoietin-2 ( $\Delta$ angiopoietin- $2_{0-2} \mathrm{~h}: P=.05$, $\Delta$ angiopoietin- $\left.2_{0-6 \mathrm{~h}}: P=.08\right)$. The change in biomarker levels between baseline and $2 \mathrm{~h}$ and between baseline and $6 \mathrm{~h}$ were not significantly different for the other biomarkers studied (surfactant protein-D, intercellular adhesion molecule-1, von Willebrand factor, IL-6, and PAI-1).

\section{Discussion}

In this study, we defined the clinical and biomarker profiles of subjects who developed postoperative ARDS. The power for the study was lowered by an ARDS event rate that was lower than the $10 \%$ we had predicted. Nonetheless, there were several findings that helped validate the hypothesis of a distinct clinical and biomarker profile for postoperative ARDS that may be validated with a larger subsequent study. The subjects who developed ARDS had lower baseline albumin levels, higher intraoperative fluid balances, and higher intraoperative peak inspiratory pressures. The subjects with ARDS were more likely to have elevations in inflammatory markers, most notably IL-8. Markers of epithelial injury (surfactant protein-D and sRAGE) and dysregulated coagulation (PAI-1) were also higher in the ARDS cohort compared with the non-ARDS groups. Importantly, both the biomarker and clinical findings were evident in the intraoperative and immediate postoperative period, well before the development of the full ARDS clinical syndrome.

Biologic markers provide an important, albeit imperfect, surrogate of the pathophysiologic processes involved in ARDS. Our study supported a greater role for exagger- 
Table 3. Intraoperative Characteristics of the Subjects With ARDS and the Non-ARDS Matched Controls

\begin{tabular}{|c|c|c|c|}
\hline Intraoperative Variable & $\operatorname{ARDS}(n=26)$ & Non-ARDS Controls $(n=51)$ & $P$ \\
\hline \multicolumn{4}{|l|}{ Fluid administration, mean $\pm \mathrm{SD}, \mathrm{mL}$} \\
\hline Crystalloid & $4,496 \pm 1,907$ & $3,346 \pm 1,544$ & .006 \\
\hline Colloid & $4,452 \pm 4,229$ & $2,731 \pm 2,511$ & .03 \\
\hline Total fluid in & $11,475 \pm 6,267$ & $8,477 \pm 4,430$ & .036 \\
\hline Total fluid out & $4,857 \pm 3,998$ & $4,303 \pm 3,037$ & .54 \\
\hline \multicolumn{4}{|l|}{ Blood product administration, mean $\pm \mathrm{SD}, \mathrm{mL}$} \\
\hline Red blood cells & $1,205 \pm 1484$ & $738 \pm 860$ & .15 \\
\hline Cell Saver & $855 \pm 857$ & $552 \pm 581$ & .11 \\
\hline Fresh frozen plasma & $760 \pm 1229$ & $426 \pm 777$ & .22 \\
\hline Platelets & $318 \pm 416$ & $180 \pm 301$ & .14 \\
\hline Cryoprecipitate & $91 \pm 140$ & $34 \pm 112$ & .08 \\
\hline Total allogeneic blood products & $2,374 \pm 3,129$ & $1,378 \pm 1,894$ & .09 \\
\hline \multicolumn{4}{|l|}{ Vital signs } \\
\hline Mean arterial pressure, mean $\pm \mathrm{SD}, \mathrm{mm} \mathrm{Hg}$ & $74.8 \pm 5.9$ & $73.3 \pm 6$ & .32 \\
\hline Tidal volume, mean $\pm \mathrm{SD}, \mathrm{mL} / \mathrm{kg}$ ideal body weight & $6.4 \pm 1.3$ & $6.9 \pm 1.2$ & .08 \\
\hline Peak inspiratory pressure, mean $\pm \mathrm{SD}, \mathrm{cm} \mathrm{H}_{2} \mathrm{O}$ & $22.7 \pm 6.5$ & $18.8 \pm 4.9$ & .006 \\
\hline $\mathrm{S}_{\mathrm{pO}_{2}}$, mean $\pm \mathrm{SD}, \%$ & $98.7 \pm 1.8$ & $99.3 \pm 1$ & .09 \\
\hline PEEP, mean $\pm \mathrm{SD}, \mathrm{cm} \mathrm{H}_{2} \mathrm{O}$ & $4.9 \pm 2.1$ & $4 \pm 1.7$ & .09 \\
\hline \multicolumn{4}{|l|}{ Intraoperative events } \\
\hline One lung ventilation, $n(\%)$ & $13(50)$ & $16(31.4)$ & .11 \\
\hline Aortic cross clamp (total), $n(\%)$ & $16(61.5)$ & $31(60.8)$ & .95 \\
\hline Aortic cross clamp time, mean $\pm \mathrm{SD}$, min & $82.4 \pm 42.8$ & $115.4 \pm 77.6$ & .08 \\
\hline Cardiopulmonary bypass total, $n(\%)$ & $19(73.1)$ & $37(72.5)$ & .96 \\
\hline Cardiopulmonary bypass time, mean $\pm \mathrm{SD}$, min & $182.9 \pm 66.7$ & $179.7 \pm 82.7$ & .87 \\
\hline \multicolumn{4}{|l|}{ Intraoperative vasoactive infusions, $n(\%)$} \\
\hline Dobutamine & $0(0)$ & $0(0)$ & $>.99$ \\
\hline Dopamine & $2(7.7)$ & $0(0)$ & .034 \\
\hline Epinephrine & $16(61.5)$ & $26(51)$ & .37 \\
\hline Milrinone & $4(15.4)$ & $10(19.6)$ & .65 \\
\hline Norepinephrine & $7(26.9)$ & $7(13.7)$ & .16 \\
\hline Vasopressin & $9(34.6)$ & $18(35.3)$ & .96 \\
\hline Phenylephrine & $1(3.8)$ & $1(2)$ & .63 \\
\hline
\end{tabular}

ated inflammation (IL-8), epithelial injury (surfactant protein-D and sRAGE), and dysregulated coagulation (PAI-1) in ARDS. In contrast to previous studies, ${ }^{20,23,34}$ we did not observe an association between markers of endothelial injury and the development of postoperative ARDS. This may indicate that endothelial injury is either less of a feature in postoperative ARDS or that it develops later in the ARDS disease course. Given that a trend toward higher angiopoietin-2 levels was observed in the ARDS cohort, it may also be that our study was underpowered to detect the difference between the 2 groups.

Although biologic markers can theoretically improve ARDS predictions, a pragmatic approach that incorporates both clinical and biomarker prediction models has yet to be developed. Our study did identify plasminogen-activator-1, IL-8, and surfactant protein-D as 3 promising candidate biomarkers to integrate into a clinical postsurgical ARDS risk prediction model. In this clinical setting, obtaining a baseline sample and an early postoperative sample (likely somewhere between $2 \mathrm{~h}$ and $6 \mathrm{~h}$ ) may be the optimal strategy for future studies by capturing both the differences in baseline of PAI-1 and the temporal trend of IL-8 and surfactant protein-D. If this strategy were to be used in the context of an ARDS prevention trial, then the narrow operational time frame for an ARDS prevention intervention would require point-of-care assays for these biomarkers. Currently, these real-time assays are not available and represent a major barrier to integrating biomarkers into the clinical trial framework. Moreover, even in enriched "high risk" populations such as ours, the overall rate of ARDS is low, which further increases the operational difficulties associated with ARDS prevention trials. ${ }^{35}$

The elevation of IL-8 in patients with ARDS and the associated implication of exaggerated inflammation in ARDS may represent a particularly attractive ARDS endophenotype to target in the context of ARDS prevention. Corticosteroids are readily available and highly effective at attenuating the endogenous inflammatory response. However, the role of corticosteroids is highly controver- 
Table 4. Outcomes of Subjects Who Developed ARDS vs Matched Controls Who Did Not Develop ARDS

\begin{tabular}{lccc}
\hline \hline \multicolumn{1}{c}{ Outcome } & $\begin{array}{c}\text { ARDS } \\
(n=26)\end{array}$ & $\begin{array}{c}\text { Non-ARDS } \\
\text { Controls } \\
(n=51)\end{array}$ & $P$ \\
\hline $\begin{array}{l}\text { Admission APACHE III } \\
\text { score, mean } \pm \text { SD }\end{array}$ & $74.6 \pm 25.3$ & $69.7 \pm 22.9$ & .43 \\
Admission SOFA score, & $7.9 \pm 3.3$ & $7.2 \pm 2.7$ & .34 \\
$\quad$ mean \pm SD & & & \\
ICU admission, $n(\%)$ & $26(100 \%)$ & $40(78.4 \%)$ & .002 \\
ICU readmission after & $5(19.2 \%)$ & $4(7.8 \%)$ & .15 \\
$\quad$ floor transfer, $n(\%)$ & & & \\
ICU length of stay, d & $3.5(1.1-5.9)$ & $1.1(0.9-2.9)$ & .036 \\
Hospital length of stay, d & $14.8(10.3-19.3)$ & $7.3(5.4-9.8)$ & $<.001$ \\
Death in the ICU, $n(\%)$ & $2(7.7)$ & $0(0)$ & .11 \\
Death in the hospital, $n(\%)$ & $4(15.4)$ & $0(0)$ & .006 \\
Death at 28 days, $n(\%)$ & $3(11.5)$ & $0(0)$ & .034 \\
Ventilator-free days & $26.2(23.2-27.7)$ & $27.7(27.5-28)$ & $<.001$ \\
&
\end{tabular}

APACHE $=$ Acute Physiology and Chronic Health Evaluation

SOFA $=$ Sequential Organ Failure Assessment scoring system

sial. Although isolated studies showed beneficial effects of systemic steroids in established ARDS, the balance of evidence does not support their routine use. ${ }^{36,37}$ In this context, biomarker-targeted delivery of corticosteroids to those with markedly elevated IL-8 may be a potential strategy to define those patients who would potentially benefit most from corticosteroid administration. Clearly, before any such undertaking, the findings of this preliminary study would have to be validated in a larger and more heterogeneous patient cohort.

This study had several strengths that deserve mention. To our knowledge, this was the first study that evaluated the temporal profile of biomarkers in post-surgical ARDS. Second, this was the first biomarker study, to our knowledge, in which the temporal profile of biomarkers was measured with reference to an individual's premorbid baseline. In all other ARDS biomarker studies, measurements were taken when a patient presented to the emergency department or hospital, typically far into the disease course. Third, several efforts were made to standardize the ARDS cases and non-ARDS controls to ensure a fair comparison. We recruited subjects with similar baseline comorbidities and presurgical risk of postoperative ARDS as measured by the preoperative surgical lung injury prediction score. We also matched closely the surgical procedure, which, again, limited heterogeneity between the subjects in the cases and the controls. Our study also used a robust multistep ARDS adjudication procedure to ensure the accuracy of the primary outcome of interest. Fourth, all biomarker analyses were performed simultaneously and in duplicate to reduce measurement bias.
This study also had several notable limitations. Most notably, the rate of ARDS development was lower than expected (5.6\% vs $10 \%$ [expected]), which reduced our overall power to detect differences in biomarker patterns. Several biologic markers showed a trend to significance (angiopoietin-2, IL-6, sRAGE), which raised concern for a type-2 error. An adequately powered study could have detected these differences and more comprehensively defined the distinct biomarker profile of postoperative ARDS. The reasons for this unexpectedly low rate of ARDS are unclear, but possible reasons include suboptimal performance of the surgical lung injury prediction score in predicting postoperative ARDS or a decline in the overall rate of ARDS from the time of study planning and surgical lung injury prediction score derivation to the time of the study conduct.

The low ARDS rate also meant that all ARDS cases identified in this study were needed for the primary analyses in evaluating the changes in biomarkers over time, which left no remaining cases for validation purposes. Because the study matched cases to controls on the surgical lung injury prediction score, it was not possible to meaningfully evaluate whether a combined surgical lung injury prediction and/or biomarker model could more effectively predict who would develop ARDS compared with surgical lung injury prediction alone. Future studies could use the most promising candidate biomarkers in this study (PAI-1, IL-8, and surfactant protein-D) in combination with the previously validated clinical variables to see if biomarkers augment clinical prediction scores. The lower ARDS rate also meant that we did not correct for multiple comparisons.

Given the predominantly hypothesis-generating study design and relatively small sample size, validation studies will be necessary to confirm our findings before any pragmatic implementation of the study results. Correcting for multiple comparisons would have increased the likelihood of false negatives and potentially missed generating hypotheses for future studies. A larger sample size would have allowed for multiple comparisons to be performed, which would have increased confidence in the results in this study. Replication of the clinical and biomarker changes reported above in a future study would help validate the hypothesis of a distinct clinical and biologic marker profile for postoperative ARDS, particularly if performed in a larger, more heterogeneous cohort.

In addition to the low rate of ARDS, the short duration of mechanical ventilation and the low mortality suggest that the enrolled study population may have a more modest overall severity of illness than what was expected. This, in addition to the single-center nature of this study and the narrow enrolled population (subjects undergoing high-risk cardiac, thoracic, or aortic vascular surgery) may limit generalizability. Moreover, the lower severity of ill- 

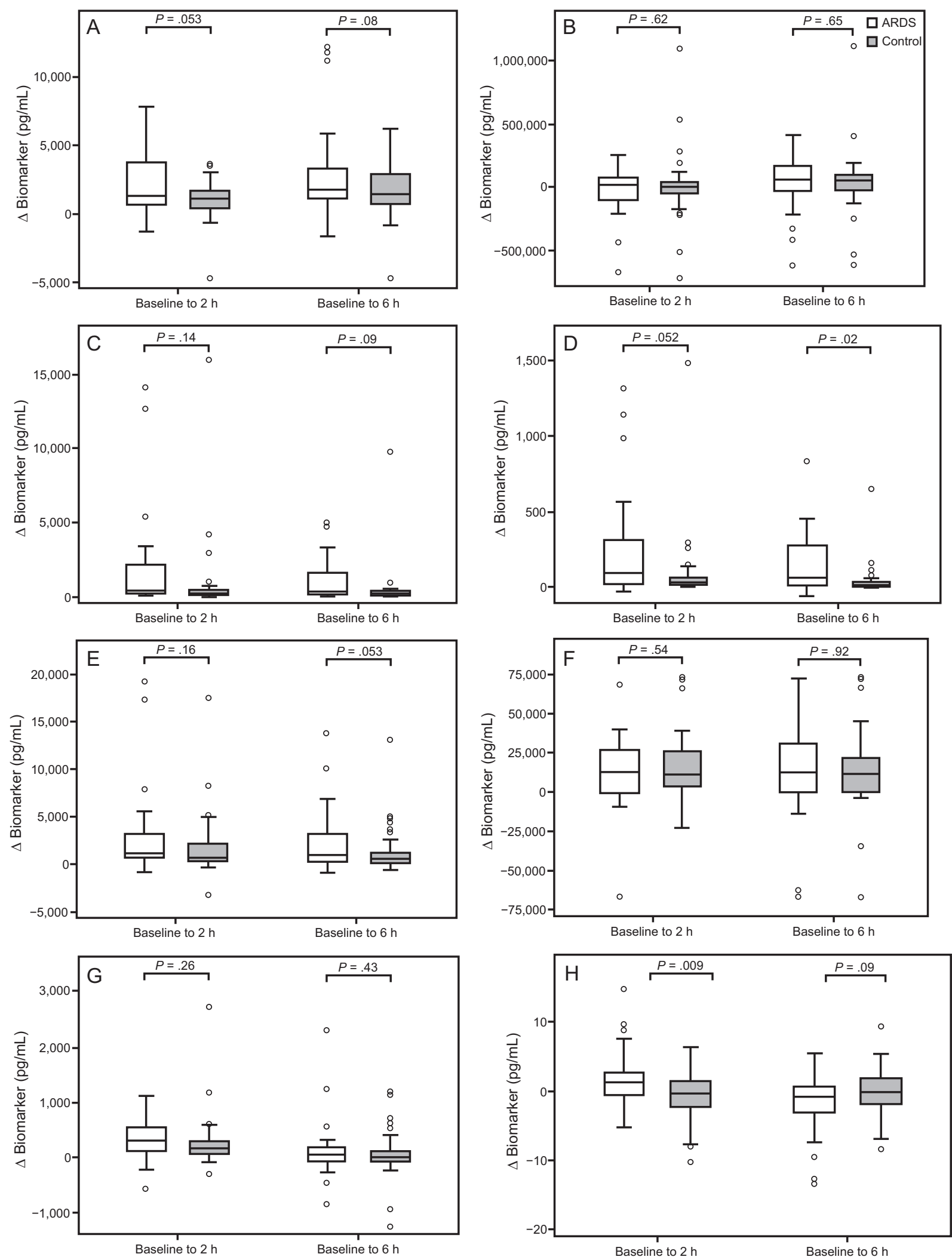

Fig. 2. Biologic markers at baseline to $2 \mathrm{~h}$ and baseline to $6 \mathrm{~h}$. Box plots represent median and interquartile range. Upper and lower limits represent the highest or lowest measured value within 1.5 times the interquartile range. Circles outside the box and whisker plots represent individual outliers. 
ness may indicate that some subjects classified as having ARDS may have cardiogenic pulmonary edema instead.

Certainly, there is considerable diagnostic ambiguity between cardiogenic pulmonary edema and ARDS in the immediate postoperative setting. To try and mitigate this ambiguity, we performed as robust an ARDS adjudication mechanism as possible, with 2 reviewers, (DJK and HY) who independently reviewed all charts in a predefined standardized manner, with Ognjen Gajic resolving any disagreements. With this, we hoped to have minimized the risk of cardiogenic pulmonary edema being misclassified as ARDS. Indeed, this ambiguity highlights the need for improved diagnostic tools for ARDS identification. Our study showed a trend toward larger increases in angiopoietin-2 and sRAGE in the ARDS group. Due to the relatively low ARDS rate and small number of ARDS cases, these findings may represent a type- 2 error, and highlight the need to investigate these findings in a larger cohort. The observational nature of this study also created potential for confounding and bias.

\section{Conclusions}

The biomarker patterns observed in this study supported a role for inflammation, dysregulated coagulation, and epithelial injury as pathophysiologic features early in the course of postoperative ARDS. IL-8, PAI-1, and surfactant protein-D are particularly promising biomarkers, and future studies should attempt to integrate these into clinical risk prediction models.

\section{REFERENCES}

1. Kor DJ, Warner DO, Alsara A, Fernández-Pérez ER, Malinchoc M, Kashyap R, et al. Derivation and diagnostic accuracy of the surgical lung injury prediction model. Anesthesiology 2011;115(1):117-128.

2. Bellani G, Laffey JG, Pham T, Fan E, Brochard L, Esteban A, et al.; LUNG SAFE Investigators, ESICM Trials Group. Epidemiology, Patterns of Care, and Mortality for Patients With Acute Respiratory Distress Syndrome in Intensive Care Units in 50 Countries JAMA 2016;315(8):788-800.

3. Ruffini E, Parola A, Papalia E, Filosso PL, Mancuso M, Oliaro A, et al. Frequency and mortality of acute lung injury and acute respiratory distress syndrome after pulmonary resection for bronchogenic carcinoma. Eur J Cardiothorac Surg 2001;20(1):30-36; discussion 36-37.

4. Acute Respiratory Distress Syndrome Network, Brower RG, Matthay MA, Morris A, Schoenfeld D, Thompson BT, Wheeler A. Ventilation with lower tidal volumes as compared with traditional tidal volumes for acute lung injury and the acute respiratory distress syndrome. N Engl J Med 2000;342(18):1301-1308.

5. Guérin C, Reignier J, Richard JC, Beuret P, Gacouin A, Boulain T, et al.; PROSEVA Study Group. Prone positioning in severe acute respiratory distress syndrome. N Engl J Med 2013;368(23):21592168.

6. National Heart, Lung, Blood Institute Acute Respiratory Distress Syndrome (ARDS) Clinical Trials Network. Wiedemann HP, Wheeler AP, Bernard GR, Thompson BT, Hayden D, et al. Comparison of two fluid-management strategies in acute lung injury. N Engl J Med 2006;354(24):2564-2575.

7. Yadav H, Thompson BT, Gajic O. Fifty Years of Research in ARDS. Is Acute Respiratory Distress Syndrome a Preventable Disease? Am J Respir Crit Care Med 2017;195(6):725-736.

8. Ware LB, Koyama T, Billheimer DD, Wu W, Bernard GR, Thompson BT, et al. Prognostic and pathogenetic value of combining clinical and biochemical indices in patients with acute lung injury. Chest 2010;137(2):288-296.

9. Parsons PE, Eisner MD, Thompson BT, Matthay MA, Ancukiewicz M, Bernard GR, et al.; NHLBI Acute Respiratory Distress Syndrome Clinical Trials Network. Lower tidal volume ventilation and plasma cytokine markers of inflammation in patients with acute lung injury. Crit Care Med 2005;33(1):1-6; discussion 230-232.

10. Meduri GU, Headley S, Kohler G, Stentz F, Tolley E, Umberger R, Leeper K. Persistent elevation of inflammatory cytokines predicts a poor outcome in ARDS. Plasma IL-1 beta and IL-6 levels are consistent and efficient predictors of outcome over time. Chest 1995; 107(4):1062-1073.

11. Fremont RD, Koyama T, Calfee CS, Wu W, Dossett LA, Bossert FR, et al. Acute lung injury in patients with traumatic injuries: utility of a panel of biomarkers for diagnosis and pathogenesis. J Trauma 2010;68(5):1121-1127.

12. Lee YL, Chen W, Chen LY, Chen CH, Lin YC, Liang SJ, Shih CM. Systemic and bronchoalveolar cytokines as predictors of in-hospital mortality in severe community-acquired pneumonia. J Crit Care 2010; 25(1):176.e7-e13.

13. Takala A, Jousela I, Takkunen O, Kautiainen H, Jansson SE, Orpana A, et al. A prospective study of inflammation markers in patients at risk of indirect acute lung injury. Shock 2002;17(4):252-257.

14. Nakamura T, Sato E, Fujiwara N, Kawagoe Y, Maeda S, Yamagishi S. Increased levels of soluble receptor for advanced glycation end products (sRAGE) and high mobility group box 1 (HMGB1) are associated with death in patients with acute respiratory distress syndrome. Clin Biochem 2011;44(8-9):601-604.

15. McClintock D, Zhuo H, Wickersham N, Matthay MA, Ware LB. Biomarkers of inflammation, coagulation and fibrinolysis predict mortality in acute lung injury. Crit Care 2008;12(2):R41.

16. Groeneveld AB, Raijmakers PG, Hack CE, Thijs LG. Interleukin 8-related neutrophil elastase and the severity of the adult respiratory distress syndrome. Cytokine 1995;7(7):746-752.

17. Christie JD, Shah CV, Kawut SM, Mangalmurti N, Lederer DJ, Sonett JR, et al.; Lung Transplant Outcomes Group. Plasma levels of receptor for advanced glycation end products, blood transfusion, and risk of primary graft dysfunction. Am J Respir Crit Care Med 2009; 180(10):1010-1015.

18. Calfee CS, Ware LB, Eisner MD, Parsons PE, Thompson BT, Wickersham N, et al.; NHLBI ARDS Network. Plasma receptor for advanced glycation end products and clinical outcomes in acute lung injury. Thorax 2008;63(12):1083-1089.

19. Jabaudon M, Futier E, Roszyk L, Chalus E, Guerin R, Petit A, et al. Soluble form of the receptor for advanced glycation end products is a marker of acute lung injury but not of severe sepsis in critically ill patients. Crit Care Med 2011;39(3):480-488.

20. Ong T, McClintock DE, Kallet RH, Ware LB, Matthay MA, Liu KD. Ratio of angiopoietin-2 to angiopoietin-1 as a predictor of mortality in acute lung injury patients. Crit Care Med 2010;38(9):1845-1851.

21. Meyer NJ, Li M, Feng R, Bradfield J, Gallop R, Bellamy S, et al. ANGPT2 genetic variant is associated with trauma-associated acute lung injury and altered plasma angiopoietin-2 isoform ratio. Am J Respir Crit Care Med 2011;183(10):1344-1353.

22. Agrawal A, Matthay MA, Kangelaris KN, Stein J, Chu JC, Imp BM, et al. Plasma angiopoietin-2 predicts the onset of acute lung injury in 


\section{BIOMARKERS IN POSTOPERATIVE ARDS}

critically ill patients. Am J Respir Crit Care Med 2013;187(7):736742.

23. Ware LB, Eisner MD, Thompson BT, Parsons PE, Matthay MA. Significance of von Willebrand factor in septic and nonseptic patients with acute lung injury. Am J Respir Crit Care Med 2004; 170(7):766-772

24. Ware LB, Conner ER, Matthay MA. von Willebrand factor antigen is an independent marker of poor outcome in patients with early acute lung injury. Crit Care Med 2001;29(12):2325-2331.

25. van der Heijden M, van Nieuw Amerongen GP, Koolwijk P, van Hinsbergh VW, Groeneveld AB. Angiopoietin-2, permeability oedema, occurrence and severity of ALI/ARDS in septic and nonseptic critically ill patients. Thorax 2008;63(10):903-909.

26. Agouridakis P, Kyriakou D, Alexandrakis MG, Prekates A, Perisinakis K, Karkavitsas N, Bouros D. The predictive role of serum and bronchoalveolar lavage cytokines and adhesion molecules for acute respiratory distress syndrome development and outcome. Respir Res 2002;3:25.

27. Calfee CS, Eisner MD, Parsons PE, Thompson BT, Conner ER Jr, Matthay MA, et al.; NHLBI Acute Respiratory Distress Syndrome Clinical Trials Network. Soluble intercellular adhesion molecule-1 and clinical outcomes in patients with acute lung injury. Intensive Care Med 2009;35(2):248-257.

28. Greene KE, Wright JR, Steinberg KP, Ruzinski JT, Caldwell E, Wong WB, et al. Serial changes in surfactant-associated proteins in lung and serum before and after onset of ARDS. Am J Respir Crit Care Med 1999;160(6):1843-1850.

29. Ware LB, Matthay MA, Parsons PE, Thompson BT, Januzzi JL, Eisner MD; National Heart, Lung, and Blood Institute Acute Respiratory Distress Syndrome Clinical Trials Network. Pathogenetic and prognostic significance of altered coagulation and fibrinolysis in acute lung injury/acute respiratory distress syndrome. Crit Care Med 2007;35(8):1821-1828
30. Christie JD, Robinson N, Ware LB, Plotnick M, De Andrade J, Lama $\mathrm{V}$, et al. Association of protein $\mathrm{C}$ and type 1 plasminogen activator inhibitor with primary graft dysfunction. Am J Respir Crit Care Med 2007; 175(1):69-74.

31. Calfee CS, Eisner MD, Ware LB, Thompson BT, Parsons PE, Wheeler AP, et al.; Acute Respiratory Distress Syndrome Network, National Heart, Lung, and Blood Institute. Trauma-associated lung injury differs clinically and biologically from acute lung injury due to other clinical disorders. Crit Care Med 2007;35(10):2243-2250.

32. ARDS Definition Task Force, Ranieri VM, Rubenfeld GD, Thompson BT, Ferguson ND, Caldwell E, et al. Acute respiratory distress syndrome: the Berlin Definition. JAMA 2012;307(23):2526-2533.

33. Byrt T, Bishop J, Carlin JB. Bias, prevalence and kappa. J Clin Epidemiol 1993;46(5):423-429.

34. Terpstra ML, Aman J, van Nieuw Amerongen GP, Groeneveld AB. Plasma biomarkers for acute respiratory distress syndrome: a systematic review and meta-analysis*. Crit Care Med 2014;42(3):691700 .

35. Kor DJ, Carter RE, Park PK, Festic E, Banner-Goodspeed VM, Hinds R, et al.; US Critical Illness and Injury Trials Group: Lung Injury Prevention with Aspirin Study Group (USCIITG: LIPS-A). Effect of Aspirin on Development of ARDS in At-Risk Patients Presenting to the Emergency Department: The LIPS-A Randomized Clinical Trial. JAMA 2016;315(22):2406-2414

36. Peter JV, John P, Graham PL, Moran JL, George IA, Bersten A. Corticosteroids in the prevention and treatment of acute respiratory distress syndrome (ARDS) in adults: meta-analysis. BMJ 2008; 336(7651):1006-1009.

37. Steinberg KP, Hudson LD, Goodman RB, Hough CL, Lanken PN, Hyzy R, et al.; National Heart, Lung, and Blood Institute Acute Respiratory Distress Syndrome (ARDS) Clinical Trials Network. Efficacy and safety of corticosteroids for persistent acute respiratory distress syndrome. N Engl J Med 2006;354(16):1671-1684.

This article is approved for Continuing Respiratory Care Education credit. For information and to obtain your CRCE

(free to AARC members) visit www.rcjournal.com 